\begin{tabular}{|c|c|c|}
\hline$\underset{P U B L I C A T I O N}{\operatorname{NIF}}$ & $\begin{array}{c}\text { International Journal of Advanced Engineering, Management and Science } \\
\text { (IJAEMS) } \\
\text { Peer-Reviewed Journal } \\
\text { ISSN: } 2454-1311 \text { / Vol-7, Issue-7; Jul, } 2021 \\
\text { Journal Home Page: } \text { https://ijaems.com/ } \\
\text { Article DOI: https://dx.doi.org/10.22161/ijaems.77.8 }\end{array}$ & (1) \\
\hline
\end{tabular}

\title{
Measuring the Readiness of applying Internet of Thing in the managing education process at high schools in Basra
}

\author{
Raghad Saleh Darweish Salem Aljaseim
}

Business Management (Electronic Management), Administration in Basra Education Directorate

Received: 09 Jul 2021; Received in revised form: 14 Jul 2021; Accepted: 21 Jul 2021; Available online: 29 Jul 2021

\begin{abstract}
Today as the Coronavirus crisis unfolds, several countries impose lockdown and social distancing to prevent a pandemic. The internet has become increasingly important for the reduction of social contact in the business world, health care, education, and industry, especially in educational institutions. This study aimed to identify the level of applying (IoT) in the management education process, identify the point of strength and weakness at high schools in Basra, and specify the current readiness. Depend on a survey, and case study methods to investigate the reality of applying (IoT) at high schools in Basra. We used a number of scientific research tools, including personal interviews and multiple field visits for schools. In addition, design a checklist to collect data necessary to find out the current reality through answer the question about four important indicators (connection, management, security and privacy, cost).

This study reached a number of conclusions, the most important of which is that most schools in Basra are not ready to use (IoT) in managing the education process. Therefore, they need more focus on these indicators to take advantage of the benefits provided by (IoT) to improve the education process.
\end{abstract}

Keyword-(IoT) Internet of Thing, Wi-Fi, readiness, Smart Classroom, important, challenges.

\section{INTRODUCTION}

The Internet of Things and related connected objects are becoming a more popular topic around the world, especially in current time to face the pandemic of coronaviruses; the IoT encompasses all sector of life such as health, transport, education, and communications. Due to the novelty of the topic and the lack of clarity of the importance of its application and adoption in facilitating the education process in current situation and more dependent on electronic learning with use. Accordingly, the research came in its importance in order to move towards building a theoretical framework, and a practical one that reflects the identification of reality Application readiness of (IoT) in high school in Basra.

The problem of the study is determined that despite the urgent desire of the competent authorities to apply the things. The application process suffers from several problems, including: The lack of the required This article can be downloaded from here: www.ijaems.com

(C2021 The Author(s). Published by Infogain Publication. infrastructure, Weak communication networks, weak protection and security of students' personal information, the high cost of providing a high-speed connection and the availability of equipment required to implement the Internet of Things. To solve this problem, and determine the current reality of the application we depend in survey and case study method to measure the readiness of apply (IoT) and depend in checklist for the most critical indicator (connection, management, security \& privacy, and cost). Through the extraction rate of the apply readiness and the percentage of readiness.

We were chosen the high schools in Basra as a field of study, for several reasons, including that these schools it suffers from a decline in the level of its services and suffers from many challenges in this field, to enhance its ability to provide the best educational services and improve the quality of the educational process.

\footnotetext{
This work is licensed under a Creative Commons Attribution 4.0 License. http://creativecommons.org/licenses/by/4.0/
} 
Therefore this research aimed to (1) Define the internet of thing (IoT). (2) The useful key for using (IoT) in manage education process and the benefits which return for each one teacher and student which facilitate the education process. (3) Determine the challenge, which face teacher and student through applying (IoT). (4) And identify the readiness of high school in Basra to apply (IoT) through specify the challenge which facing them.

The most important finding of the study was that most schools are not ready to implement (IoT) because they do not provide a connection for all students and the necessary device, lack of training; which requires teachers to gain experience. Low security and privacy in the applications they use, which need to be improved more importantly.

\section{LITERATURE REVIEW}

\section{1- Internet of Thing (IoT) definition}

The (IoT)seen as an industrial adaptation of the Internet of Things, is known by various of names, including "(Industrial Internet) as GE terms it, (Internet of Everything) term proposed by Cisco, Rockwell Automation's (IoT Industrial Revolution), IBM's (Smarter Planet) or the European (Industry 4.0) or (Industrie 4.0) (original German term), respectively French (Industrie du Futur), (Industry of the Future). The term Industrial Internet of Things (abbreviated as IIoT, I-IoT, I2OT or I2OT) is used to represent what is expected to revolutionize the industry, by merging the digital and real industry. The Internet of Things is defined as follows":(Turcu \& Turcu, 2018)

A huge network consistence intelligent devices and equipment that connect between itself and human around the world.

- A platform from smart objects that led to the formulation and tracking of complex operations over long distances.

There is no general concept of IoT, according to (Whitmore, Anurag, \& Xu, 2015), The technical and sociotechnical viewpoints are the two primary conceptualizations. The first, a purely technological viewpoint, sees the (IoT) as a collection and ecosystem of technical artifacts. It's described in terms of these artifacts and their abilities.

While (Patel, Patel, \& Scholar 2016)determined the concept (IoT) into three categories: (1) Persons to persons, (2) Persons to device, (3) device to device, communicating via World Wide Web.

The (IoT)is defined as : (Khan, 2018)

- A global network that connects a sector of intellectual and industrial goods development, technologies, and services through the wider community.

- Is a wireless system of advanced devices that enables accurate organization and monitoring of complicated activities over relative distances.

- Focuses on the digitization of all physical resources and inventions from beginning to end, also their incorporation into electronic influence of the external with stakeholders.

As we can see, the definition of IoT is not clear, and the distinction frequently depends on the unique vision of the organization in terms of IoT components that are regarded more important. In other point, various definitions of the (IoT) with different of organizations goals want to achievement.

Sometimes difficult to define the word IoT because there are several different meanings depending on who is doing the defining. The basic idea behind the Internet of Things is to "connect things, allowing the "things" to interact with one another and humans to engage with them." Depending on the circumstances and purpose of use (a global framework for the knowledge society, enabling improved services by integrating (physical and virtual) objects utilizing existing and emerging compatible technological tools").(Bude \& Kervefors, 2015)

In a word, it is an accessible and complete network of combined smart devices can operate automatically to collect, organize, resource, acting as the situation need and adaptation with the environment change. The Internet of Things (IoT) is one of the most recent developments in ICT, allowing for global communication and control of sensors, computers, users, and data. (Madakam, 2015).

The concept of (IoT) also known as (Web of Things), which has a huge range of applications such as tracing for healthcare for personal, services for home can make automatically, Nonetheless, there is no clear concept to IoT, and its scope is hazy due to a wide range of implementations of IoT systems. The IEEE project to define the Internet of Things seeks to bring together a generic description, design, and technology to help people better understand the term and its applications. (Alreshidi \&Ahmad, 2019)

According to the following, we will define the (IoT) as a number of thing/s objects that connect with each other through a network at any time or place. Talk, analyze, and evaluate information automatically in real time to make the right decision and improve the management of operation education. In addition, achieve the benefit for each individual teacher and student. 


\section{2- The important of Internet of Thing in management education process:-}

In order to catch courses, the school must have high-speed Wi-Fi and video recorders. International cooperation and social interaction should be encouraged in smart schools. Sensors with an auto-reorder feature must be available for tracking school supplies and inventory. In smart schools, there must be signposts for coping with emergency situations. The standard of the learning environment would improve if the previous IOT devices are used in any school. It will also foster a creative environment among students at the school. The percentage of students who save lives at school will also rise. It would also reduce the amount of time spent on conventional teaching techniques in educational organizations, better management and protection can be accomplished. In every way, the proposed system is beneficial to both students and teachers.(Abdelbasset et al. 2018)

- Students from all over the world will be able to communicate with each other:

- The students can interact with their teachers, bearleader, and lecturers from anywhere in the world using the new IOT technologies, they can sit in their home or in class and communicate with them in any time.

- Encourage high safety and growth outcomes:

- IoT technologies provide a number of alternatives for energy, environmental organization, mobility and road safety, all of this provides the school with improved educational experiences. For example, schools can save energy by using IOT technology programs to monitoring energy and management it for reinvesting the savings to improve the instructional process.

- Ensure that students learn in a stable and healthy environment:

- Because it is essential to maintain students' safety and protection, the (IoT) provide the school with different electronic devices such as microphones, webcams, monitoring, and security equipment. Which provide with sensor for rapid notice, alarms, and dedicate the require steps to substantial boost the protection and stability of educational organization.

- Obtain Parity for everything:

- The connection among anything in the universe provides students with customized learning programs. Furthermore, accessible computers, resources, and applications make learning more accessible by achieving parity with the classmates.
- Convert students into innovators:

- The Internet of Things (IoT) provides students with various devices to make decisions in order to improve their ability to understand, build, and control themselves.

The Internet of Things (IoT) is changing traditional education into flexible, adaptive, and more successful elearning with a strong structure that includes a huge number of digital devices associating in the education process. The integration of IoT in learning environments offers up endless possibilities for effective training. It contributes to the development of energy-efficient and costeffective education systems by automating routine operations outside of the teaching process. IoT has an influence on education in a variety of ways, including student learning interests and curriculum creation, as well as assisting instructors in providing personalized materials and improving student outcomes. There is different application for use (IoT) in education process such as Google Apps (classroom, translate, Google books, etc.), different courses for any subject across website like (edX, Coursera, my Homework , Khan Academy).(Lakshminarayanan\& McBride, 2015)

The advantages of IoT in education are as follows:(Bajracharya \& Blackford, 2018)

- It helps schools to improve campus security, track critical resources, and improve information access.

- It generates an intelligent lesson plan that can be reached anywhere and at specific moment.

- It reduces the cost of a heating system, ventilation, and air-conditioning system. Through using Intelligent systems It keeps the room at a require temperature without wasting resources. Include auto windows, smart records, and programs that monitor airflow relaying on the number of people in the class.

- Minimize lighting costs across automatically switches the lights based on room occupancy and natural lighting from windows and doors to

- It helps instructors by automating operations like turning on projections and lowering lights when presentations are used, among other things, and so on.

- It aids in the improvement of each student's results.

- All data gathered and kept from each sensor over time is in the server or database, where it could be analysed to identify techniques that are more effective. 
- It provides individualized and flexible education, or guidance that is suited to the requirements of the learners.

- It contributes to each student's improved performance.

- It makes for a context-aware, all-encompassing learning environment.

- It strengthens communication between educators and students.

- It boosts a student's success.

- It raises the responsibility of the learner.

Today many school realized the technology's potential to enhance teaching, learning, and evaluation and Technology is more important for a modern school aiming to be more differentiated, increase acceptance, maximize loyalty, and achieve targeted goals. However, instilling confidence in students is a challenging process. It requires highly educated leadership to be in charge to get perfect methods to educate the students the new and latest invented technologies in this field. As the (IoT) has grown in popularity, several schools have begun to concentrate on the technologies and applications of the IoT. This method is also used at the university level. The Internet has become profoundly embedded in school systems, and e- education become most important in the modern school systems. (IoT) can provide many benefits such us: - (Aldowah, Rehman, Ghazal, \& Umar, 2017)

- In all education systems, IoT can improve operational performance.

- IoT can help classroom teaching by enhancing the learning process, increasing learning tools, improving learning methods and techniques, and increasing management performance.

- Reduces management costs learning tools accessible on smartphones, electronic books, for example, are more interesting and interactive.

Incorporating IoT into the educational process has several significant advantages such us: - (Sade , Folasade, \& Omoyele, 2015)

- Data collection and analysis is simple for research purposes.

Data was gathered, categorized, and evaluated throughout time depending on their related knowledge to obtain fresh observations or inventions on the object. This approach is becoming increasingly easy as IoT is implemented. Once the procedure has been set up (identifying the item, associating that data, and proposing that data be supplied to other servers for analysis), students may collect information and advance through various study programs from any location. Students will have access to data to improve their analytical accuracy 24 hours a day, seven days a week.

\section{- Enhancement Learning Skills}

Use IoT in education process increases students' ability to learn new topics in particular. Students may touch objects, and details about them can be shown for them to learn. Each object will be fitted with an RFID) Radio-frequency identification) tag, which contain all data about this object which student can put it in front of an RFID reader. And use this data to learn foreign language vocabulary.

- Enhanced Mobile

Increase dependence on use (IoT) in the education process, which provide more resources and will be easily shared among students and teachers.

\section{- Competence and Reliability}

IoT will minimize misunderstandings that are smoothly committed through minor processes, and it will minimize the risk of impersonation to a reasonable extent because most operation handled driven with efficiencies by this technology, such as manual selecting students for data sharing, and so on.

\section{- Online Education}

The use of IoT into the educational process will support or facilitate distance learning. Experts in difficult-to-find fields are made available using this method. Students who are absent from school for health, ethnic, or religious reasons can fully engage in a classroom activity while at home.

- Improved Assistive Technology for Unique Students

Learning gets simpler for exceptional learners that require assistance or support in order to study. Minorities and handicapped learners, according to the IoT, will have access to advanced learning and peer-to-peer contact, as well as student-to-teacher engagement, improving their chances of success.

In the current time, the (IoT) will improve the learning process and bring more benefits for each one of the teachers and students. Learning will be easier, and teachers can complete their tasks more easily. IoT tools are expected to provide a more appealing, versatile, interactive, and quantifiable educational environment that meets the diverse needs of a large number of students and teachers. Teachers will be less waste time on routine tasks. Smart devices can allow students in a limited period to comprehend difficult concepts. They can also track performance automatically and use neuro-sensors to evaluate students. More schools today try to incorporate an (IoT) in their management through the special situation of corona virus and social distance. 


\section{3- The challenge of using (IoT) in the education management}

Now education struggle and face difficulties and chances because of using (IoT).The swift developing of computing and (IoT) technical Cloud storage, predictive analytics, and establishing a new digital culture are all very beneficial in not only developing the basic values for teaching and research and bringing it to a completely new level of evolution, but also in developing a (IoT) community and promoting a modern digital culture. The Internet of Things (IoT) is increasing digital speed in educational institutions. With more internet options and easy access to instructional content in both structured and unstructured formats, IoT is a significant break from traditional educational models in that it incorporates other areas through boost the impact of large data accessible through social media.

IoT Challenge in Education process is one of the most important technology development drivers, and is one of the sectors with the most possibilities for economic and social development. As a result, all parties involved, from engineers to developers, companies, and consumers, are confronted with a variety of issues that must be solved. (Hassan et al., 2018). The following are part of the educational system's challenges:

- A lack of general frameworks for a universal educational environment.

- Necessary rethink existing psychology, social constructionism, and other educational ideas etc.

- The difficulty of academics to accept modern technologies.

- Difficulty in ensuring security and safety to deploy for different devices in the cloud.

- The cost of building IoT may be prohibitively high.

- $\quad$ Some IoT technologies are incompatible, making it impossible to use them.

As the view for (Gul et al. 2017)applying the IoT in education process can face numerous challenges in to achieve successfully integrating IoT devices in a classroom setting, including network capacity, strong connections (Wi-Fi), web analyses, policy and security, safety, students' access to the system, teacher preparation, and equipment expenses, and other. The following parts go through some of the difficulties:

\section{- Security and Privacy}

Using (IoT) data will be kept in network of linked devices across Internet, and when sensors begin to detect and gather data from students, their security and privacy will be threatened. Any cyber attack might expose personal data such as a student's healthcare records, parents financial background, or other personal information.

This article can be downloaded from here: www.ijaems.com

\section{- Reliable Wi-Fi Connection}

Today increase the demand for educational technology, such as strong wireless networks which offered high speed connection for audio and video streaming for manage education process.

\section{- Administration}

Some devices and apps are mismatched, making it hard for the organization to build (IoT) system that would be both safe and usable by all users. For efficient IoT deployment, an educational system must guarantee that both its (IoT) equipment and teaching techniques supporting the usage of IoT in the lesson. While technology has dangers and possible stumbling blocks, educational institutions might benefit from studying and experimenting with IoT alternatives.

\section{- Expensive}

The entire setup of a Smart educational process may be rather expensive. As a result, the price of facilities and equipment has become an issue.

And (Abdul-Rahman et al., 2020) discuss the challenge as the following:

- Educational cyber security: Various data, which is transferred via the Internet, is kept in systems based on these technological advancements. They are largely made up of various devices that are linked to them and begin to compute and gather data from students, putting the students' security and privacy at danger. Any data leak might reveal a student's private information, such as health files, personal economic status, and other personal documents.

- Credible (Wi-Fi) connection: the significance of contemporary technology in education, as well as the necessity need for it without interruption with high speed wireless connection and high quality for support education process with multimedia.

- Intelligence classrooms: While there are dangers and problems connected with technology, education systems can benefit from studying and engaging with IoT solutions.

- Cost of (IoT) :These modern technical advances, including all of essential devices necessary to establish a comprehensive educational system at an inexpensive price, may be utilized to thoroughly prepare educational institution. As a response, the cost of gadgets and equipment has become a new issue for educational professionals and corporations.

- Healthcare: Because of the widespread use of security cameras and remote sensors, can be 
monitored the student and determine their temperature and can make update the medical history of the student

An education provider may need to discuss numerous issues, for example, system transfer speed, reliable Wi-Fi Interaction, web evaluation, public safety, stability, ease of access of operating systems for understudies, teacher preparing, and equipment cost, among others, in order to successfully incorporate IoT devices in an educational domain. Some of the difficulties are discussed as the below. (Nagamalla \& Sastry 2018)

- Privacy concerns: Because information is stored on internet and can access from many user which put the security of personal information for student in danger

- Efficient Wi-Fi Connection: There is always a demand for new improvements in education, such as fast distant networks that allow data transfer to audio and video streaming in the classes.

- Management: unperfected devices and application may prevent to build strong and accessible network in (IoT) which need special technological tools to enhance classroom. Most innovation can content risk and limitation, which need effective management to deal with it.

- Cost: The overall cost of establishing an IoTbased educational environment might be high. As a result, the cost of electronics and infrastructure is another measuring stick.

Based on the above we can be brevity the challenge of using IoT in education management in connection problem which related with the strong $\mathrm{Wi}-\mathrm{Fi}$, and the number of time the connection disconnect, availability of connection in different country. Problem of security and privacy for using IoT in education management can put the information for students in danger any network penetration due to leak information for the student or for their family. and the more important which force many country the cost for provide the internet access around the country and provide the student with the device to use IoT in learning, finally the training for teacher, managing school, and student which need cost and time and preside the for the important using IoT and benefit which return to them.

\section{METHODOLOGY}

This study used the survey method through a sample survey that includes the characteristics of whole the society under study, to be able to gather a lot of information in a relatively short period of time. And the good choice of the sample whose characteristics represent the whole society, the generalizations characteristics can be applied to the entire society, based on that we selected a sample of high schools according to the geographical location, from the center of Basra city and the outskirts, which will includes the characteristics of the whole society being studied.(Kothari, 2004)

The chosen the case study method is an integrated system and combines archival searches, interviews, questionnaires, and observation, the case study contributes to a better understanding of the individual phenomena, and the organizational and political processes of society. (Varela et al., 2021)

This research depend on:

1- Interview: With all specialists in the school to talk about the challenge for using (IoT) in the Managing, the educational processto get a clear view of the actual application of the (IoT).

2- An opinion poll and the use of the checklist: in order to identify the most prominent obstacles facing each of (principals, assistants, teachers, students) about the extent of the application of the Internet of Things in managing the educational process

We choice the sample according to survey method which represent the whole characteristic of society according to the geographical location, from the center of Basra city and the outskirts as shown in the table (1).

Table 1: The study sample

\begin{tabular}{|r|l|l|}
\hline No & Name & Location \\
\hline 1. & Al-Hashimiyat High School for Girls & \multirow{2}{*}{ Basra Center } \\
\cline { 1 - 2 } 2. & Al-Elaf High School for the Distinguished & \multirow{2}{*}{ Al-Zubiar } \\
\hline 3. & Umm Al Banin High School for Girls & \\
\hline 4. & Harir High School for Girls & \multirow{2}{*}{ Al-Midaina } \\
\cline { 1 - 2 } 5. & KarimaAhl al-Bayt High School & \\
\hline 6. & Science City High School & \\
\hline
\end{tabular}

This article can be downloaded from here: www.ijaems.com 


\begin{tabular}{|r|l|l|}
\hline 7. & Al-Zawraa high school & \multirow{2}{*}{ Abu Al-Khaseeb } \\
\hline 8. & Al-Marwa High School for Girls & \\
\hline 9. & Al-Muhajireen High School for Boys & Al Qurnah \\
\hline 10. & Qurna high school for girls & \\
\hline
\end{tabular}

Source: prepared by the researcher

It was applied on each school (Manager,2Assistant Director, 10 teacher, and30student) in the high school from different situation in Basra as shown in table (1). The study time limits in $(1 / 3 / 2021-1 / 5 / 2021)$ to collect information through a checklist prepared for this purpose about the most challenges facing apply (IoT) in managing the educational process which fall under four indicators:

1- Connection.

2- Management.

3- Security and privacy.

4- Cost.

And we extracted the rate of the apply readiness and the percentage of readiness. By using the triple scale in the checklist for readiness indicators challenge requirements to know the degree of importance of each answer to the specific paragraphs in each field. Using the scale graded according to the following data: (ready, partially ready, and not ready; with weights were given for each paragraph of the scale according to the following: $(0,1,2)$.

In this research, we relied on the quantitative expression of the answers in the analyzed checklists by using the weighted arithmetic mean to express the extent of conformity to the application. and the percentage of the actual application extent by the Directorate for the purpose of increasing the verification of the weighted arithmetic mean that was reached, and by using the following laws:

1- Weighted $\begin{gathered}\text { arithmetic } \\ \text { (readiness) }=\frac{\text { Sum }(\text { Weight } * \text { Repetition })}{\text { Sum Repetition }} \ldots . .(1)\end{gathered}$
2-
Percentage (readiness) $=\frac{\text { arithmetic mean }}{\text { Highest scale weight }} * 100 \%$
$\quad \ldots . . . . .(2)$

Readiness rates (2) were considered very well because they indicate total readiness and indicate full implementation, while readiness rates (1) were considered acceptable, indicate medium readiness, and include implemented, partially applied and readiness rate 0 is not applied.

\section{DISCUSSIONTHE RESULT}

\section{- Connection indicators:}

According to the checklist described in table (2), the percentage of readiness was $(40 \%)$, which the researcher saw as an unacceptable percentage that needs to be improved in order to apply (IoT) in the education process management. Due to the situation in villages and the countryside, internet access is also not available for both students and teachers, and the internet connection quality is inadequate; most networks in Iraq are generation $3 \mathrm{G}$, which needs to be upgraded to $4 \mathrm{G}$ or $5 \mathrm{G}$.To use (IoT), speedily wireless network with wide band to transfer data smoothly for support education process.

Most schools have websites and social contact variables where students can access lessons and download videos and documents, but need more improvement by publishing all the lessons throughout the year. The usage of (IoT) necessitates the use of power for thousands devices signaling and transferring data to one another, which consumes power. Therefore, we need to reduce battery depletion and power usage. You cannot rely on (CPU) capacity for all IoT devices, which are restricted and expensive to integration network. This creates even more issues in Iraq, which is suffering from an energy deficit. Aside from power and CPU usage, bandwidth consumption is an impediment to IoT connectivity.

The costs of bandwidth on a communication link is considerable, especially while there are tens of billions of IoT devices on a network delivering request/response signals to your server. To manage all of this data, the big cloud challenge necessitates a large-scale server farm, which necessitates a lightweight network capable of effortlessly transporting data between users and servers. In addition, need servers are completely flexible; you can adjust your bandwidth, capacity, memory, and other hosting plan components at any time to suit your needs. In addition, we need a wide variety of basic security features to secure your files, such as free DDoS protection and robust on-site physical security safeguards. 
Table.2: The checklist for Connection indicators

\begin{tabular}{|c|c|c|c|c|}
\hline No & The paragraphs & \multicolumn{3}{|c|}{ The readiness } \\
\hline \multicolumn{2}{|r|}{ Connection } & Ready & Partially & Not ready \\
\hline 1. & An internet connection is available for both students and teachers & & $\checkmark$ & \\
\hline 2. & Internet connection quality and number of failures & & $\checkmark$ & \\
\hline 3. & $\begin{array}{l}\text { The school have website and social contact variable to student } 24 \\
\text { hours }\end{array}$ & & $\checkmark$ & \\
\hline 4. & $\begin{array}{l}\text { Their power utilization management is designed for high- } \\
\text { performance devices with processors, screens, and } \\
\text { communication interfaces that require different amounts of } \\
\text { power. }\end{array}$ & & $\checkmark$ & \\
\hline 5. & $\begin{array}{l}\text { A massive server problem necessitates a multiple servers farm to } \\
\text { manage large amounts of data }\end{array}$ & & & $\checkmark$ \\
\hline 6. & the weight & 2 & 1 & $\mathbf{0}$ \\
\hline 7. & Repetition & $\mathbf{0}$ & 4 & 1 \\
\hline 8. & Result & $\mathbf{0}$ & 4 & $\mathbf{0}$ \\
\hline 9. & Apply readiness & & 0.8 & \\
\hline 10. & Readiness & & $40 \%$ & \\
\hline
\end{tabular}

Source: Prepared by the researcher

\section{- Management indicator:}

According to the checklist described in table (3), the percentage of readiness was $(20 \%)$, an unacceptable percentage that needs to be more interest to enhance it in order to apply (IoT) in education process. because the financial situation for all country school can't provide the student with suitable device to avoid mismatched between them and limit access for only study purpose, therefore it make difficult to manage the system and keep it safe and used for all the user in the server.

The system needed to provide with special procedure to handle with any error in real time Through provide a support and maintenance team to deal with any system error can face the student or teacher on the server. School not provided with camera, which can connected to internet for manage and monitor students, locate position in real time to safe security environment in school, which can prevent any unforeseen occurrences from occurring. Depended on electronic lesson and provide student with graphic textbook, this includes multimedia with capacity to add notes to easy the manage and modify lesson in the suitable way for each individual student to understand the lesson.

Training teacher and student is the important subject need more interest to apply (IoT) they need to know how they could deal with smart devices and distance learning to achieve the benefit they could have from use (IoT). In addition, they should know the challenge, which they face it especially about privacy and security. Moreover, we notice the lack of training courses for each one teacher and student that need more interesting.

Table.3: The checklist for Management indicators

\begin{tabular}{|l|l|c|c|}
\hline No & \multicolumn{1}{|c|}{ The paragraphs } & \multicolumn{2}{c|}{ The readiness } \\
\hline \multicolumn{1}{|c|}{ Management } & $\begin{array}{c}\text { Ready } \\
\text { Partially } \\
\text { ready }\end{array}$ & $\begin{array}{c}\text { Not } \\
\text { ready }\end{array}$ \\
\hline $\mathbf{1 .}$ & $\begin{array}{l}\text { Schools supply students with suitable electronic devices and integrated } \\
\text { among them to complete education process. }\end{array}$ & $\checkmark$ & \\
\hline $\mathbf{2 .}$ & $\begin{array}{l}\text { Provide with the procedures to handle errors in a timely manner and } \\
\text { avoid system failure and misused. }\end{array}$ & & $\checkmark$ \\
\hline
\end{tabular}

This article can be downloaded from here: www.ijaems.com 


\begin{tabular}{|c|c|c|c|c|}
\hline 3. & $\begin{array}{l}\text { Provide school with camera connected to internet to monitor student and } \\
\text { locate position in real time. }\end{array}$ & & $\checkmark$ & \\
\hline 4. & $\begin{array}{l}\text { Supply students with } 3 \mathrm{~d} \text { graphics books that include clips and the } \\
\text { opportunity to take notes. }\end{array}$ & & $\checkmark$ & \\
\hline 5. & $\begin{array}{l}\text { Training teacher for use this device and dealing with student in smart } \\
\text { classroom. }\end{array}$ & & $\checkmark$ & \\
\hline & the weight & 2 & 1 & $\mathbf{0}$ \\
\hline & Repetition & $\mathbf{0}$ & 2 & 3 \\
\hline & Result & $\mathbf{0}$ & 2 & $\mathbf{0}$ \\
\hline & Apply readiness & & 0.4 & \\
\hline & Readiness & & $20 \%$ & \\
\hline
\end{tabular}

\section{Source: Prepared by the researcher}

\section{- Security and privacy indicators:}

According to the checklist described in table (4), the percentage of readiness was (30\%), its low percentage to apply (IoT) and need more focus on security and privacy. Security must be a top priority in applying IoT. Must protect the Participants data and provide with assurance from theft for all IoT devices and connected data sources. Depending on secure devices and protocol that protect for any cyber threats, exposing it in real time.

Dependency on (IoT) and deal with huge amount of information require many application and procedures to protect information; any security incident might expose sensitive data about a student's medical history, family's economic background, or other personal details. Therefore, should notify students on where and how their personal information can be used and accessed, and then give capabilities that help students to disable specific forms of information gathering and sharing.

Also should instruct student about security so that participants do not engage in illegal behavior patterns when using their Device. The website of school provide the limit security and privacy across warnings for use information. And use backup for information to save it from any damage can exposed to computer by save it in different location and use Google drive. Not variable any monitor for operation time of the device, which is very necessary to avoid the wrong use for the device. Provide technologies can be Students are watched around the day and each week, and determine their location can be noted at any moment. such as camera and sensor to alarm any breaking in the system security in to school.

Table.4: The checklist for Security and privacy indicators

\begin{tabular}{|l|l|l|l|l|}
\hline No & \multicolumn{1}{|c|}{ Security and privacy } & \multicolumn{3}{c|}{ The readiness } \\
\hline \multicolumn{2}{|c|}{} & $\begin{array}{c}\text { Ready } \\
\text { ready }\end{array}$ & Not ready \\
\hline $\mathbf{1 .}$ & $\begin{array}{l}\text { Use Application to protect the privacy information for student } \\
\text { and their parents from danger any person's document, a parents } \\
\text { economic source, or another private entity. }\end{array}$ & $\checkmark$ & \\
\hline $\mathbf{2 .}$ & Use backup procedures to preserve data. & & $\checkmark$ & \\
\hline $\mathbf{3 .}$ & Monitor operational time of the devices & & & $\checkmark$ \\
\hline $\mathbf{4 .}$ & $\begin{array}{l}\text { notify students on where and how their personal information } \\
\text { can be used and help them to disable specific information } \\
\text { gathering and sharing }\end{array}$ & & & \\
\hline $\mathbf{5 .}$ & $\begin{array}{l}\text { Provide technologies can be monitored student through 24 } \\
\text { hours and their position may be detected at every moment. }\end{array}$ & & $\checkmark$ & $\mathbf{0}$ \\
\hline
\end{tabular}

This article can be downloaded from here: www.ijaems.com 


\begin{tabular}{|c|c|c|c|}
\hline Repetition & $\mathbf{0}$ & $\mathbf{3}$ & $\mathbf{2}$ \\
\hline Result & $\mathbf{0}$ & $\mathbf{3}$ & $\mathbf{0}$ \\
\hline Apply readiness & \multicolumn{3}{|c|}{$\mathbf{0 . 6}$} \\
\hline Readiness & \multicolumn{3}{|c|}{$\mathbf{3 0 \%}$} \\
\hline
\end{tabular}

\section{Source: Prepared by the researcher}

\section{- Cost indicator:}

In the table (5) include the checklist for the fourth indicator challenge in (IoT) the readiness was $(60 \%)$ and it acceptable percentage. Although the use of (IoT) will help to save paper and textbooks, the IoT system will require three important things that will be more expensive:

- Hardware refers to a variety of machines that perform critical tasks and functions, such as sensors, control devices, servers, and so on.

- Software for receiving, analysing, and storing sensor data

- Application that allows users to communicate with and control IoT devices.
For that apply (IoT) need to financial budget for provide the essential need for (IoT) system. The internet access is one of the essential point in (IoT) we notice the more used network in Iraq is old generation $3 \mathrm{G}$ and it need more cost from the government and Communication Company to update it for $4 \mathrm{G}$ or $5 \mathrm{G}$. For apply (IoT) we need network with high speed to deal with huge data. From the checklist and observation, we notice most family they could provide their children with the device for each one, so they almost share same device to make homework or join classroom, which create problem each time for them. Most school force challenges to provide teacher with require training because the cost of training which need classroom and devices and lecturers. Use (IoT) contributed to reduce the error ratio by automatic education management.

Table.5: The checklist for Cost indicators

\begin{tabular}{|c|c|c|c|c|}
\hline No & The paragraphs & & The readi & \\
\hline & Cost & Ready & Partially & Not ready \\
\hline 1. & $\begin{array}{l}\text { Cost for variable internet access high for student and their } \\
\text { parents }\end{array}$ & & $\checkmark$ & \\
\hline 2. & Cost for the device needed high for student and their parents & & $\checkmark$ & \\
\hline 3. & $\begin{array}{l}\text { Cost of training teacher for essential skills to use IoT in manage } \\
\text { education process }\end{array}$ & & $\checkmark$ & \\
\hline 4. & Reduce cost by digitalize textbook and save paper. & & $\checkmark$ & \\
\hline 5. & $\begin{array}{l}\text { Reduce cost for error ratio by automatic education } \\
\text { management. }\end{array}$ & $\checkmark$ & & \\
\hline & the weight & 2 & 1 & $\mathbf{0}$ \\
\hline & Repetition & 1 & 4 & $\mathbf{0}$ \\
\hline & Result & 2 & 4 & $\mathbf{0}$ \\
\hline & Apply readiness & & 1.5 & \\
\hline & Readiness & & $60 \%$ & \\
\hline
\end{tabular}

Source: Prepared by the researcher.

\section{CONCLUSIONS AND RECOMMENDATIONS}

Based on what was presented in the theoretical framework and field analysis of the results that were reached and discussed, we were reached to a number of conclusions and recommendation as follows:-

This article can be downloaded from here: www.ijaems.com
1- Poor communication networks available in the country

2- Lack of servers with a wide bandwidth to deal with a huge amount of information and provide high speed in data processing. 
3- The lack of the required infrastructure of computers, cameras and smart boards, which is one of the necessary requirements for implementing the Internet of Things.

4- The lack on provided the suitable infrastructure to apply (IoT) make difficult to manage and protect the huge data, it lead to system failure.

5- Lack of awareness among students and even teachers about the importance of the application of the Internet of things and what are the advantages that can be obtained as a result of the application.

6- lack the security and privacy procedures increase the possibility of penetration and leakage of personal data for both students and teachers, which puts privacy at risk

7- Because of weak communication networks, which makes the network vulnerable to any penetration

8- The high cost required to provide devices and equipment and to hold the necessary training courses for the application.

9- Most high school in Basra are not ready to use (IoT) in education process.

10- Enhance the network communication and provide the school with network high speed such $4 \mathrm{G}$, or $5 \mathrm{G}$.

11- The need to raise awareness of the importance of using the Internet of Things and the benefits obtained from its use, whether for the student or the teacher.

12- Provide the school require infrastructure to apply (IoT).

13- Provide the technical support and specify the procedure to deal with any error in real time.

14- Giving the utmost importance to privacy protection programs and archiving process to preserve information.

15- Providing a financial allocation for providing the infrastructure and the require courses to training how to use and deal with the (IoT) application and protect the personal information.

16- A study of the importance of using the Internet of Things and its impact on the quality of education.

17- A study of the obstacles to using the Internet of things and their impact on the possibility of application

This article can be downloaded from here: www.ijaems.com

\section{REFERENCES}

[1] Alreshidi, Abdulrahman; Ahmad, Aakash (2019). Architecting software for the Internet of Thing based systems. Future Internet, 11(7).online source

[2] Aldowah, H., UlRehman, S., Ghazal, S., \&Naufal Umar, I. (2017). Internet of Things in Higher Education: A Study on Future Learning. Journal of Physics: Conference Series, 892(1). online source.

[3] Bajracharya, B., Blackford, C., \&Chelladurai, J. (2018). Prospects of Internet of Things in Education System. CTE Journal. ISSN 2327-0160 (Online). Volume 6. Number 1, online source.

[4] Turcu, C. O., \& Turcu, C. E. (2018). Industrial internet of things as a challenge for higher education. International Journal of Advanced Computer Science and Applications, 9(11), 55-60. online source

[5] Abdul-Rahman Al-Malah, Duha Khalid, Hussein Hamed Khudair Jinah, and Haider Th Salim ALRikabi. 2020. "Enhancement of Educational Services by Using the Internet of Things Applications for Talent and Intelligent Schools." Periodicals of Engineering and Natural Sciences 8(4):2358-66. doi: 10.21533/pen.v8i4.1744.

[6] Meinert, Edward, Michelle van Velthoven, David Brindley, Abrar Alturkistani, Kimberley Foley, Sian Rees, Glenn Wells, and Nick de Pennington. 2018. "The Internet of Things in Health Care in Oxford: Protocol for Proof-of-Concept Projects." JMIR Research Protocols 7(12):1-12. doi: 10.2196/12077.

[7] Patel, Keyur K., Sunil M. Patel, and P. G. Scholar. 2016. "Internet of Things-IOT: Definition, Characteristics, Architecture, Enabling Technologies, Application \&amp; Future Challenges." International Journal of Engineering Science and Computing. doi: $10.4010 / 2016.1482$.

[8] Khan, Shakir. 2018. "Modern Internet of Things as a Challenge for Higher Education Shakir." IJCSNS International Journal of Computer Science and Network Security, 18(12):34-41. online source

[9] Sade Kuyoro, Folasade Osisanwo, and Omoyele Akinsowon. 2015. "Internet of Things (IoT): An Overview." Pp. 53-58 in 3rd International Conference on Advances in Engineering Sciences and Applied Mathematics (ICAESAM'2015), March 2324, 2015 London (UK). London (UK) Atoms: International Institute of Engineers.online source

[10] Nagamalla, Vishwesh, and J. K. R. Sastry. 2018. “An Overview on the Challenges and Impact of IoT in Future Education." International Journal of Pure and Applied Mathematics 120(6):243-60. 120(6):243260. online source

[11] Whitmore, A., Agarwal, A., \& Xu, L. da. (2014). The Internet of Things-A survey of topics and 
trends.Information Systems Frontiers2014 17:2, 17(2), 261-274. online source

[12] Bude, C., \& Kervefors, A. (2015). Internet of Things Internet of Things Exploring and Securing a Future Concept. Degree Project in Communication Systems, First Level Stockholm, Sweden, 19-28. online source

[13] Research Methodology: Methods and Techniques- C. R. Kothari - Google Books. (n.d.). Retrieved July 23, 2021, online source

[14] Varela, Miguel, Paula Lopes, and Rosa Rodrigues. 2021. "Rigour in the Management Case Study Method: A Study on Master's Dissertations." Electronic Journal of Business Research Methods 19(1):pp1-13. doi: 10.34190/ejbrm.19.1.2072.online $\underline{\text { soure }}$

[15] Madakam, Somayya. (2015). Internet of Things: Smart Things. International Journal of Future Computer and Communication, 4(4), 250-253. online $\underline{\text { source }}$

[16] Abdel-Basset, M., Manogaran, G., Mohamed, M., \& Rushdy, E. (2019). Internet of things in smart education environment: Supportive framework in the decision-making process. Concurrency Computat Pract Exper, 31(10),1-12.online source

[17] Lakshminarayanan, Vasudevan., \& McBride, Annette. C. (2015). The use of high technology in STEM education. Education and Training in Optics and Photonics: ETOP 2015. doi:10.1117/12.2223062, online source

[18] Hassan, Qusay F., Khan, Atta ur Rehman., \& Madani, Sajjad A. (2018). Internet of things: Challenges, advances, and applications. Boca Raton: Taylor \& Francis, CRC Press.

[19]Gul, Shahla, Muhammad Asif, Shahbaz Ahmad, Muhammad Yasir, Muhammad Majid, and M. Sheraz Arshad Malik. 2017. "A Survey on Role of Internet of Things in Education." IJCSNS International Journal of Computer Science and Network Security 17(5):159-65.online source 